American J. of Engineering and Applied Sciences 1 (2): 131-135, 2008

ISSN 1941-7020

(C) 2008 Science Publications

\title{
A Simple Tubesheet Layout Program for Heat Exchangers
}

\author{
${ }^{1}$ S. Murali and ${ }^{2}$ Y. Bhaskar Rao \\ ${ }^{1}$ Department of Mechanical Engineering, Jaya Prakash Narayan College of Engineering, Mahabubnagar, \\ Andhra Pradesh, India \\ ${ }^{2}$ Scientist $\mathrm{G}$ and Head, Design Engineering Division, Indian Institute of Chemical Technology, \\ Hyderabad, Andhra Pradesh, India
}

\begin{abstract}
The development of tubesheet layout program for shell and tube heat exchangers is presented in this study. Program is written in AutoLISP language, which provides standard tubesheet layout drawing as per standard codes and non standard tubsheet in AutoCAD Environment. The program computes the optimal number of tube count and lays out drawing with respecting constraints, including the shell ID, number of passes, center to center distance of tubes and tube outer diameter. Tubesheet layout drawing can be used as template for actual tubesheet. Furthermore the program is validated with open literature and shown good agreement with it. Besides the tubesheet for Heat exchangers this method can be extended to the tube counts of sheave plates and perforated plates of distillation column and Cooling Towers.
\end{abstract}

Key words: Heat exchanger, Tube count, Tubesheet drawing, Auto LISP

\section{INTRODUCTION}

Heat exchanger finds in wide variety of applications such as chemical processing, refrigeration, air conditioning, space heating and power production. Shell and tube heat exchanger is a most common heat exchanger, consists of a series of tubes, through which one of the fluids runs. The second fluid runs over the tubes to be heated or cooled. It is robust and its shape makes it well suited to pressure operation. The number of tubes which can be accommodated within a given shell inside diameter is termed as the tube count. For a given shell inside diameter, Tube outside diameter, pitch and pitch angle, tube count depends on the major factors type of heat exchanger, Nozzle diameter, tube pass and entrance area.

In view of the practical industrial importance many researchers have manually laid down tubesheet and counted the number of tubes for the given size of shell diameter and presented in the table formats ${ }^{[1-3]}$. However, preliminary design Tube count ${ }^{[4]}$ can be computed using the Eq. 1. This takes tube pass and tube orientation in to account but not the layout type, nozzle size. The limited tube count table made researchers to investigate further using computer technologies.
Tube Count $=\frac{0.785 * \mathrm{CTP} * \mathrm{D}_{\mathrm{s}}^{2}}{\mathrm{CL} * \mathrm{P}_{\mathrm{t}}^{2}}$

Medeiros and Lerioz ${ }^{[5]}$ presented a simple geometry based computational procedure in Delphi language for the determination of tube dimensional parameters. A sorting procedure is used to approximately place the tubes according to the tube distance to the shell center. Tube count search procedure developed only for one and two tube pass heat exchangers. Tube count discrepancies of $1 \%$ were observed.

Ardalan et $a l^{[6]}$ suggested solution for calculating the tube count in a shell and tube heat exchanger. A visual $\mathrm{C}$ program is developed to compute the number of tubes. Three straightforward algorithms are used to carry sorting procedure. Plane sorting and Tube sorting methods have been employed to find out tube bundle center which will fit maximum number of tubes. However, no importance is given to accuracy of tube count.

Tubesheet for many industrial services never be restricted to limited shell size or three pass. Program must accommodate important parameters like different passes, different orientation, nozzle diameter, free height and pass partition plates and must follow the standard $\operatorname{codes}^{[8,9]}$. The final tubesheet drawing

Corresponding Author: S. Murali, Department of Mechanical Engineering, Jaya Prakash Narayan College of Engineering, Mahabubnagar, Andhra Pradesh, India, Tel: +918542-275313, Fax: +918542-275587 
generated must be accurate enough to develop true tubesheet.

Programming in $\mathrm{C}$ and Delphi suffers poor graphical representation. However, these can be used to develop output document in dxf to view the drawing. But, this necessitates the programmer/user to use $2 \mathrm{D}$ drafting package which makes the program more expensive. Rusty Genser et al..$^{[7]}$, describes Auto CAD has greatest adaptability and key element of this adaptability is AutoCAD' $\mathrm{s}$ built in programming language , Auto LISP. With Auto LISP user can virtually write own commands and redefine others. Being the native language does not require additional drawing package to view the output. Further, use of Dialog control language boxes enriches the program and provides user friendly environment

In the present study a simple program is developed to find tube count and to generate tubesheet drawing. This program accounts for shell diameter, tube diameter, tube orientation, any number of tube passes, pass partition plates and free height. Program uses Standard codes for Mechanical details. Besides the tubesheet for Heat exchangers this method can be extended to the tube counts of sheave plates and perforated plates of distillation column cooling towers where the diameter may be non standard and much different from heat exchanger.

\section{TUBESHEET LAYOUT PROCEDURE}

Figure 1 shows standard tube patterns ${ }^{[8]}$ generally used in industrial Heat Exchangers. The tube layout is defined by the characteristic angle and the corresponding definition of the tube pitch. The $30^{\circ}, 45^{\circ}$

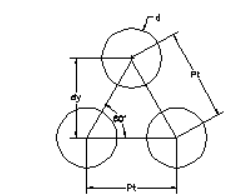

Rotated Triangular $d x=$ Pt, $d y=$ Pt $\operatorname{Sin} 60$

19

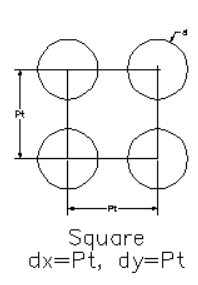

10

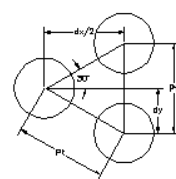

Triangular

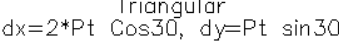

$1 b$

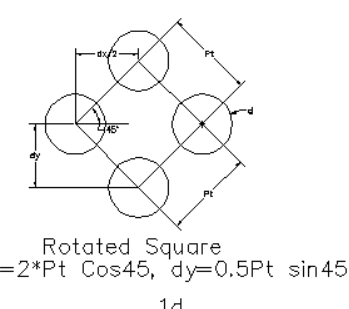

14
Fig. 1: Standard Tube Pattern and $90^{\circ}$ layouts are given but $60^{\circ}$ layout is not considered because it produces lower effectiveness in pressure drop to heat transfer conversion for singlephase flow applications and therefore is not generally recommended. The $30^{\circ}$ staggered layout has the highest tube density. Therefore, the largest heat transfer surface within a given shell can be obtained by $30^{\circ}$ layout. This layout has also a high effectiveness of pressure drop to heat transfer conversion. Therefore, it should be primarily considered while choosing the appropriate tube layout. However, it causes the highest pressure drop for a given tube pitch. The $45^{\circ}$ staggered layout has also a high effectiveness of pressure drop to heat transfer conversion. However, when comparing with $30^{\circ}$ layout, it is not more advantageous because it permits only about $85 \%$ of tubes within a given shell. An important advantage of $45^{\circ}$ layout is that the pressure drop for a given pitch is less than for a $30^{\circ}$ layout. Another advantage of $45^{\circ}$ layout is the possibility of shell-side cleaning from outside by mechanical means, if sufficient clearance between tubes is allowed (approximately $7 \mathrm{~mm}$ ). The $90^{\circ}$ in-line layout should not be used in laminar shell-side flow, but it has also a high effectiveness of pressure drop to heat transfer conversion in turbulent flow. The cleaning convenience of shell-side from outside is the same as for $45^{\circ}$ layout. The $90^{\circ}$ layout should be considered as an alternative to the $30^{\circ}$ or $45^{\circ}$ staggered layout, especially if low pressure drop is desired.

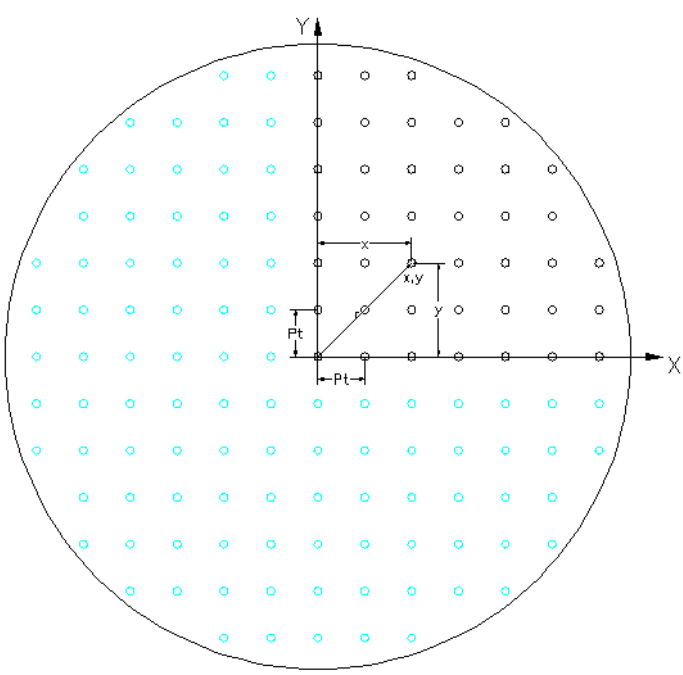

Fig. 2: Tubesheet Layout Construction

Figure 2 shows tube layout construction. The method by which it is developed can be understood by the 
following lines. The tube center $(\mathrm{x}, \mathrm{y})$ of a tube in Cartesian co-ordinates is expressed as:

$$
\begin{aligned}
& x_{i}=C+i d x \\
& y_{j}=j d y
\end{aligned}
$$

Where:

$\mathrm{i}=1,2,3 \ldots \mathrm{n}$

$\mathrm{j}=1,2,3 \ldots \mathrm{n}$

For Rectangular pattern

$\mathrm{C}=0$ for both even and odd rows

For other than Rectangular pattern

$\mathrm{C}=0$ for odd rows

$\mathrm{C}=0.5 \mathrm{P}_{\mathrm{t}}$ for even rows

$\mathrm{dx}$ and dy are increments along $\mathrm{x}$ and $\mathrm{y}$ directions respectively and these values in terms of tube pitch $(\mathrm{Pt})$ for various orientation can be obtained from the Table 1.

Pass partition plates reduce the tube count, however these are compulsory for multi pass heat exchangers. Pass partition plate standard thickness is find from standard codes. If the pass partition plate thickness B is considered the Eq. 2 and 3 becomes:

$$
\begin{aligned}
& x_{i}=B+C+i d x \\
& y_{j}=B+j d y
\end{aligned}
$$

Radial distance of tube center which predicts the location of tube within the shell diameter is given by:

$$
r=\sqrt{x_{i}^{2}+y_{j}^{2}}
$$

The limit of tube to lie inside the shell diameter is given by:

$$
\mathrm{r} \leq \frac{\left(\mathrm{D}_{\mathrm{s}}-\mathrm{d}\right)}{2}
$$

The construction of tubesheet layout is not complicated compared to previous works. Quadrant portion of shell diameter is filled using above equations. Rectangular tubesheet rows are generated without offset from vertical axis where as for other than rectangular pattern each even row is offset by distance equal to one half of $\mathrm{dx}$ from vertical axis. Program is designed in such a way that layout initialized with or without offset from center of shell or adjusts the pass partition plate position such that it accommodates maximum number of tubes in the quadrant. The tubes generated earlier are mirrored about $y$-axis and whole is mirrored about $\mathrm{x}$-axis.

Program extracts the number of tie rods and tie rod diameter as per standards and positions at appropriate

Table 1: Incremental Values $\mathrm{dx}$ and dy for different tube orientations:

\begin{tabular}{llllll}
\hline No. & Increment & Triangular & $\begin{array}{l}\text { Rotated } \\
\text { triangular }\end{array}$ & Square & $\begin{array}{l}\text { Rotated } \\
\text { square }\end{array}$ \\
\hline 1 & $\mathrm{dx}$ & $2 \mathrm{Pt} \operatorname{Cos} 30$ & $\mathrm{Pt} \operatorname{Cos} 60$ & $\mathrm{Pt}$ & $2 \mathrm{Pt} \operatorname{Cos} 45$ \\
2 & $\mathrm{dy}$ & $\mathrm{Pt} \operatorname{Sin} 30$ & $\mathrm{Pt} \operatorname{Sin} 60$ & $\mathrm{Pt}$ & $0.5 \mathrm{Pt} \operatorname{Sin} 45$ \\
\hline
\end{tabular}

location by replacing tubes. The program is capable of accommodate pass partition plates. The output of the program is generated in AutoCAD drawing document. The drawing document is included by most of the details required for tubesheet layout. This output can be given directly to a plotter/printer for hard pint out. The user has provision to modify tubesheet layout if necessary.

\section{RESULTS AND DISCUSSION}

The user friendly environment is enriched by dialog control boxes. The input parameters shell diameter, tube diameter, tube orientation, tube pitch, number of passes and type of tubesheet such as Ribbon type, quadrant type and mixed type must be supplied by the user in input dialog box. Figure 3 and 4 shows the output of tubesheet layouts for rectangular 4 pass mixed horizontal and triangular 4 pass horizontal. The layout are drawn for a base configuration of Shell diameter $889 \mathrm{~mm}$, Tube diameter $25.4 \mathrm{~mm}$ on Tube

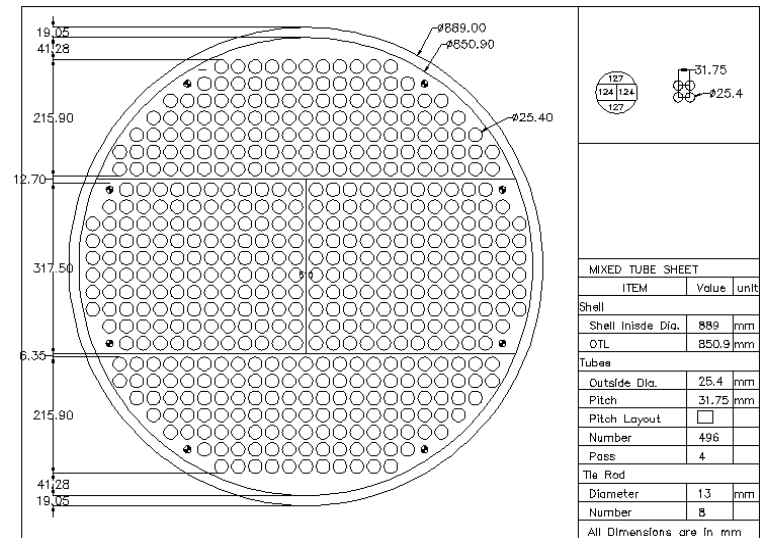

Fig. 3: Tubesheet layout for 4 pass mixed horizontal

pitch 31.75. The output tube counts for these configurations are 496 and 560. The partition plate thickness, tie rod diameter and number of tie rods are 
automatically extracted from standard codes. Extra entry space is allowed to minimize the contraction effect of the fluid entering. These output drawings can be directly given to plotter or printer for proof and can be used template for actual tubesheet layout.

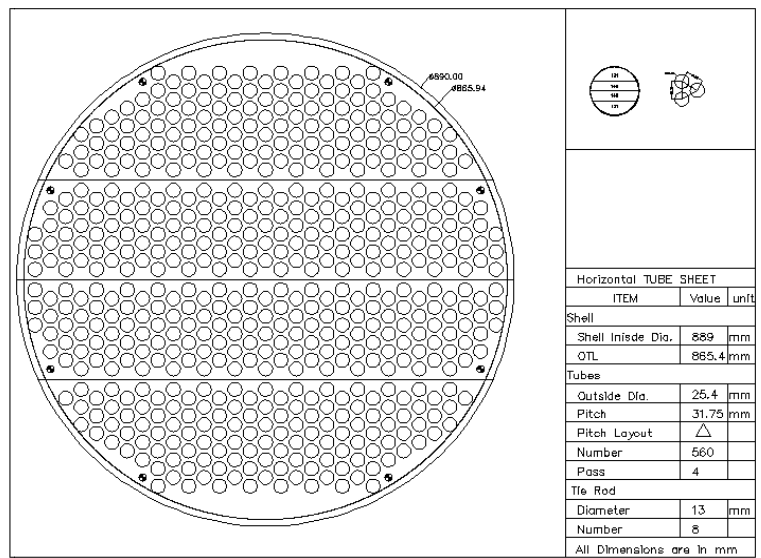

Fig. 4: Tubesheet layout for triangular 4 pass horizontal

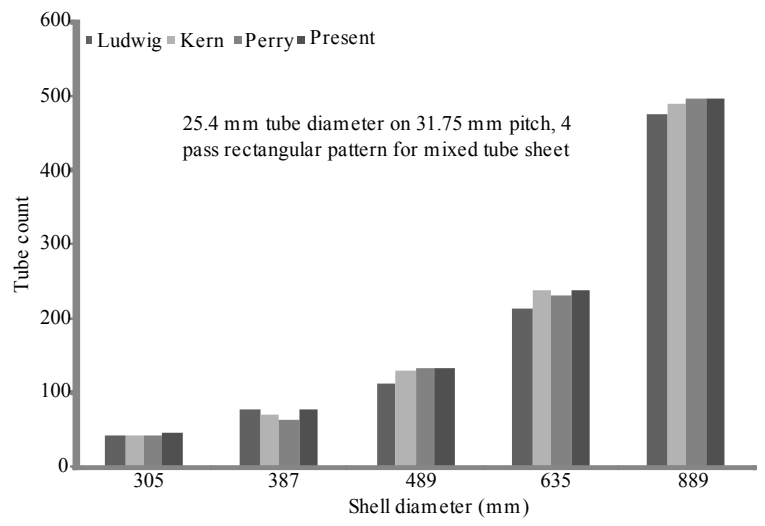

Fig. 5: Tube count vs shell diameter 4 pass

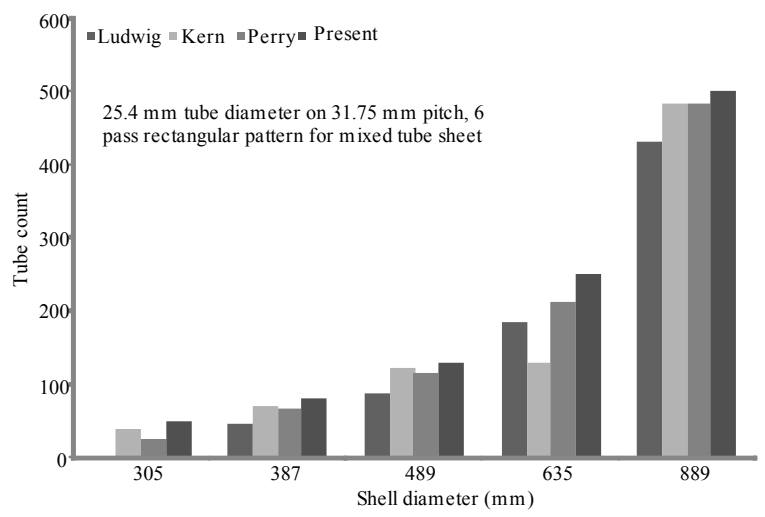

Fig. 6: Tube count vs shell diameter for 6 pass
Comparison of present program results with the open literature ${ }^{[1-3]}$ is represented in form of graphs as shown in Fig. 5 and 6. These are presented for 4 pass and 6 pass mixed horizontal. These depict that for given input parameters the present study gives more tube count. The variation of tube count may be due to conditions and absence of availability of OTL in tube count tables.

\section{CONCLUSIONS}

Auto LISP program is developed to produces optimal tube layout for standard and non standard tube count. The output drawing can be used as template for actual tubesheet. This method can be extended to the tube counts of sheave plates and perforated plates of distillation column. Program work for any number of passes for both SI and FPS units. For non standard Tube count present program draws more number of tubes compared to tube count Tables.

\section{ACKNOWLEDGEMENT}

The authors acknowledge the help and encouragement given by $\mathrm{M} / \mathrm{S}$ Indian Institute of Chemical Technology, Hyderabad and M/S Jayaprakash Narayan College of Engineering, Mahabubnagar in preparing this study.

\section{NOMENCLATURE}

CL - Tube layout constant

CTP - Tube count Calculation Constant

$D_{s} \quad-$ Shell Diameter

$P_{t} \quad$ - Tube Pitch

\section{REFERENCES}

1. Perry, 1950, Chemical Engineers Hand Book. $3^{\text {rd }}$ Edition, McGraw-Hill Book Company Inc., New York.

2. Kern, D.Q., 2005. Process Heat Transfer, $11^{\text {th }}$ Reprint, McGraw-Hill Book Company Inc., New York.

3. Ernest, E. and Ludwig, 1977. Applied Process Design for Chemical and Petrochemical Plants. Volume 3, $3^{\text {rd }}$ Edition, Gulf Publishing Company, USA.

4. Kakac, S. and H. Liu, 1997. Heat Exchangers Selection Rating and Thermal Design. CRC Press, New York. 
5. Medeiros, M.S. and A.J.K. Lerioz, 2005. A Procedure for Tube Count Determination in Single and Multiple Pass Tubular Heat Exchangers, Engenharia Termica (Thermal Engineering), Volume 4, No. 2, p 97-107.

6. Ardalan Sadighian, Leili Mirmontazeri, Ohammad and Toossi Fatollah Farhadi, 2006. A New approach in tube count for tubular heat exchanger, Proceedings of the WSEAS/IASME International Conference on Heat and Mass Transfer, Miami USA. January 18-20, p 19-22

7. Rusty Genser and Joseph Smith, 1992. Maximizing AutoLISP. New Riders Publishing, Carmel, Indiana, USA.
8. TEMA, Standards of the Tubular Exchanger Manufacturers Association, 1998. Tubular Exchangers and Manufacturers Association, Inc., 7th Edition, New York.

9. BIS, Indian Standard Specification for Shell and Tube Type Heat Exchangers, 2007. Bureau of Indian Standards IS: 4503-1967, New Delhi. 